\title{
Shaped by the Rules. How Inducement Regulation Will Change the Investment Service Industry
}

\author{
by
}

\author{
ENRICO RiNo RESTELLI*
}

\begin{abstract}
Inducement regulation is intended to target the conflict of interests between financial advisors and their clients. Nonetheless, it may also represent a 'public policy device' meant to conform the activity of European distributors with investor protection goals; indeed, by selecting the conditions under which distributors can freely collect inducements, the European regulator simultaneously shapes the market for financial services. Accordingly, 'spot advice' (which poorly performed in the past) is indirectly banned by the quality-enhancement provision set forth in art. 24 MiFID II, and the acknowledged importance of on-going monitoring of the portfolio opens up the collection of inducements linked to the provision of 'periodic advice'. Since this new regime will probably increase the overall costs of investment advice enlarging the 'advice gap', the European regulator tries also to foster the development of FinTech permitting the collection of inducements even outside the strict provision of investment advice. Nevertheless, the concerns regarding investor protection raised by FinTech services (which allow only a mere 'self-assessment' of the investor's profile) suggest a broader interpretation of inducement regulation, with the purpose of enabling investment firms to provide low-cost financial advice capable of effectively encompassing every stage of the investment relationship, from the early assessment of clients' characteristics and objectives to the on-going management of the investments ('simplified advice').
\end{abstract}

$$
\text { Table of Contents } \quad \text { ECFR 2021, 640-668 }
$$

1. Introduction $\ldots \ldots \ldots \ldots \ldots \ldots \ldots \ldots \ldots \ldots \ldots \ldots \ldots \ldots$

2. Beyond Conflicts of Interests: Inducement Regulation as a 'Public Policy Device' .........................

3. MiFID II Inducement Regulation $\ldots \ldots \ldots \ldots \ldots \ldots \ldots$

4. The Changing Market for Investment Services: The Rise of FinTech and the Role of Financial Advisors . . . . . . . . . . . . . . . . .

5. The Architecture of MiFID II Investment Services: The Perspective of Inducement Regulation . . . . . . . . . . . . . . . . . .

6. Fee-Only Independent Advice $\ldots \ldots \ldots \ldots \ldots \ldots \ldots$

7. The 'Quasi-Independent Advice' and the 'Open-Architecture’ Requirement

* Research fellow, Università degli Studi di Milano-Bicocca. 
8. The New Market for Investment Services: Between FinTech... . . . . . . . . 658

9. ...And 'Periodic Advice' (Follows) . . . . . . . . . . . . . . . . . . . . . 660

10. The 'Advice Gap' and the Need for a Broader Interpretation of MiFID II Inducement Provisions . . . . . . . . . . . . . . . . . . 661

11. A New Role for Financial Advisors: The 'Simplified Advice' . . . . . . . . . 665

12. Concluding Remarks . . . . . . . . . . . . . . . . . . . 666

\section{Introduction}

With the exception of the Netherlands, the business model of European distributors is mostly based upon 'inducements': ${ }^{1}$ commissions, fees and other nonmonetary benefits typically paid back to financial intermediaries by asset managers for the distribution of their products.

Such a remuneration scheme may create a severe conflict of interests between distributors and their clients. For this reason, MiFID II and its implementing legislation tightened the requirements for the collection of inducements, aiming at filling the fallacies showed by the former regulation.

1 Art. 168a of the Dutch Market Conduct Decree prohibits the collection of any inducement associated with the provision of investment services to retail clients (see Olha $O$. Cherednychenko, "Freedom of Contract in the Post-Crisis Era: Quo Vadis?", European Review of Contract Law, 2014, 401 and Larissa Silverentand/Jasha Sprecher/Lisette Simons, Inducements, in: Danny Busch/Guido Ferrarini (ed.), Regulation of the EU financial markets - MiFID II and MiFIR, 2017, p. 205. For a cross-country analysis, see Jeremy Burke/Angela A. Hung, "Financial Advice Markets: A Cross Country Comparison”, https://www.rand.org/pubs/research_reports/RR1269.html, last accessed 23 July 2019, 2015. In particular, as to the United Kingdom, in 2006 the Financial Service Authority started the so-called Retail Distribution Review ('RDR'), in order to prevent the conflict of interest stemming from the collection of inducements (see Financial Services Authority, "A Review of Retail Distribution”, www.fca.org.uk, 2007; George A. Papaconstantinou, "Investment Bankers in Conflict: The Regime of Inducements in MiFID II and the Member States' Struggle for Fairness", European Review of Contract Law 2016, 356; and Gerard McMeel, "International Issues in the Regulation of Financial Advice: A United Kingdom Perspective - The Retail Distribution Review and the Ban on Commission Payments to Financial Intermediaries”, St. John's L. Rev. 2013, 595, though highlighting that mis-selling was mainly caused by "the inadequacy of the training and monitoring of [advisers'] performance provided by the companies employing them"). Indeed, according to art. 6.1A.4R. of the Conduct of Business Sourcebook, both independent and restricted advisers providing investment services to retail clients "must only be remunerated for [their] personal recommendation" with upfront fees directly paid by the client (see also art. 2.3.1, implementing MiFID I delegated regulation). 
Although conflicts of interests are the main target of inducement regulation, this new set of rules will also indirectly change the very business model of European distributors. Indeed, it is very likely that distributors will have to shift their organization either towards fee-only independent advice (as the Netherlands have already did) or amend the contents and the features of their 'traditional' investment services in order to make them compliant with the new MiFID II provisions. Of course, the stricter these rules are, the more 'disruptive' such a change is going to be.

In accordance with these premises, this article intends to examine how - and to what extent - inducement regulation is going to shape the European distribution systems of investment products, assessing also whether the new rules are able to adequately protect retail investors in the recent technological and 'cultural' evolution of financial markets (sections 2-4). From this new perspective, the article will analyze the overarching architecture of MiFID II investment services, discussing in more detail the role of the new inducement regulation in modeling the provision investment advice (sections 5-9). Nonetheless since MiFID II permits the collection of inducements only when they are able to enhance the quality of the investment services offered by the distributor this new regime will probably increase the overall costs of investment advice, thus enlarging the so-called 'advice gap' (section 10). Because FinTech - and especially robo-advice - may represent only a partial solution, section 11 will attempt to solve this problem, while section 12 will conclude.

\section{Beyond Conflicts of Interests: Inducement Regulation as a 'Public Policy Device'}

As already mentioned, the broad diffusion of inducements raises serious concerns about investors' protection. Indeed, since competition among investment products depends mostly on the selection of the proper distribution channel, issuers could intensify efforts and allocate resources to strengthen their relationships with investment firms rather than improve the quality of their products. On the other hand, distributors - looking for a more favorable remuneration - may neglect clients' best interests and product suitability. Such practices could result in low-quality investment products, biased advice, poor asset allocation and eventually mis-selling. ${ }^{2}$

2 Ex multis, see Andrea Perrone, "Tanto rumore per nulla? Per un ripensamento della disciplina sugli inducements", Banca borsa e titoli di credito 2016, 137; John Armour/Dan Awrey/Paul L. Davies/Luca Enriques/Jeffrey N. Gordon/Colin Mayer/Jennifer Payne, Principles of Financial Regulation, 2016, p. 239; Andreas Hackethal/Roman Inderst/Steffen Meyer/Steffen Meyer, "Trading on Advice”, https://papers.ssrn.com/sol3/papers. 
For these reasons, the European regulator traditionally looks at inducements as a harmful source of conflict of interests, ${ }^{3}$ imposing on distributors both organizational requirements and conduct of business rules. ${ }^{4}$ Every investment firm, indeed, must "take all appropriate steps to identify and to prevent or manage conflict of interests ... caused by the receipt of inducements". ${ }^{5}$ Furthermore, the illicit collection of inducements is deemed to be a per se violation of the general duty to "act honestly, fairly and professionally in accordance with the best interest of the client" (art. 24, para. 9, MiFID II). ${ }^{6}$

With the same purpose - considering the deep inconsistency between these investment services and the rebate of commissions - art. 24, para. 7 and 8, MiFID II radically bans the collection of inducements (except for minor nonmonetary benefits) associated with the provision of independent advice and portfolio management. ${ }^{7}$

cfm?abstract_id=1701777, last accessed 23 July 2019, 2010; Karel Lannoo/Jean-Pierre Casey, The MiFID Revolution, 2009, p. 115; and Niamb Moloney, How to Protect Investors. Lessons from the EC and the UK, 2010, p. 257, pointing out that "commission-based remuneration, and remuneration-based incentive structures related to the distribution of proprietary products" may have "a very considerable potential to misalign incentives" encouraging "biased advice, failures to provide debt reduction advice, poor product selection and inappropriate advice to switch products, all of which can be exacerbated in difficult market conditions when investors are already vulnerable to market risks". Not surprisingly, the conflict of interest generated by inducement-based investment advice is well documented also in the U.S. financial system, where "brokerage firms have been known to pressure - or strongly encourage - their representatives to provide services based not on client needs but, instead, on the firms' financial objectives and associated compensation incentives" (Anita K. Krug, "Investors' Paradox", Journal of Corporation Law 2018, 131; see also Neal M. Stoughton/Youchang Wu/Josef Zechner, "Intermediated Investment Management”, Journal of Finance 2011, 947).

3 See Stefan Grundmann/Philipp Hacker, Conflict of interests, in: Danny Busch/Guido Ferrarini (ed.), Regulation of the EU financial markets - MiFID II and MiFIR, 2017, p. 192; Perrone (fn. 2), 137; Danny Busch, "MiFID II: Stricter Conduct of Business Rules for Investment Firms”, Capital Markets Law Journal 2017, 376; and Silverentand/Sprecher/Simons (fn. 1), p. 205. Among U.S. scholars, see Jeremy Burke/Angela A. Hung/ Jack Clift/Steven Garber/Joanne K. Yoong, "Impacts of Conflict of interests in the Financial Services Industry”, https://www.rand.org/pubs/working_papers/WR1076.html, last accessed 23 July 2019, 2015.

4 See Filippo Annunziata, Considerazioni in merito alla disciplina dei c.d. incentivi (note a margine degli artt. 52 e 73 del Regolamento Intermediari), in: Roberta D’Apice (ed.), L'attuazione della MiFID in Italia, 2010, p. 559; Perrone (fn. 2), 137; Niamb Moloney, Eu Securities and Financial Markets Regulation, 3th ed., 2014, p. 808.

5 Art. 23, para. 1, MiFID II.

6 Art. 24, para. 9, let. $b$, MiFID II.

7 See Grundmann/Hacker (fn. 3), p. 193, emphasizing that "the market for independent services attempts to reduce conflict of interests to a minimum by removing their core 
2.1 Although correct, this interpretation fails to capture the 'other side' of inducement regulation: namely, the role it can actually play in shaping the distribution system of retail investment products.

As a matter of fact, the profitability of European distributors relies mostly on the commissions paid back by issuers and asset managers. Therefore, the regulation of inducements and, in particular, the 'free spaces' granted to them by art. 24 MiFID II (= the conditions under which inducements can be lawfully collected) are intended to have a substantial impact on the provision of investment services by financial intermediaries. Indeed, distributors cannot rashly renounce to collect inducements, and so they will have to 'adjust' their business model in order to make it compliant with MiFID II provisions. ${ }^{8}$ Hence, by selecting the criteria for the licit collection of inducements, the European regulator is also shaping the features and the contents of investment service provision, aiming at indirectly steering distributors towards investors' protection.

From this perspective, European inducement regulation not only represents a solution to a conflict of interest problem; but it also acts as a 'public policy device' meant to conform the conduct of distributors towards a specific paradigm, in order to preserve market trust and prevent the negative externalities stemming from the breach of the fiduciary relationship that bounds every advisor with its clients. ${ }^{9}$

element; first, one of the, perhaps even the, key source of conflict advice"; Busch (fn. 3), 352 questioning the distinction "between independent and non-independent advice" instead of prescribing "basic requirements for good quality advice"; Moloney (fn. 4), p. 802; and Paolo Giudici, Independent Financial Advice, in: Danny Busch/Guido Ferrarini (ed.), Regulation of the EU financial markets - MiFID II and MiFIR, 2017, p. 147.

8 Under MiFID I regime, Lannoo/Casey (fn. 2), p. 116 noted that since 'trail commissions' represented "a major source of revenue for firms with large distribution networks", there was "a clear commercial imperative for distributor to maintain the status quo", urging the European regulator to take a different path.

9 Due to heavy asymmetries of information and cognitive biases, retail investors traditionally rely on professional advisors in order to access financial markets (see Francesco Denozza, "Law and Power in a World with No Transaction Costs: An Essay on the Legitimating Function of the Coasian Narrative", https://papers.ssrn.com/sol3/papers.cfm? abstract_id=1361613, last accessed 23 July 2019, 2009, emphasizing also the sharp asymmetry of power that characterizes such investment relationships). Therefore, conflict of interests, poor advice, and inadequate investment protection not only expose investors to severe financial losses but may also exacerbate system risk and threaten financial stability, thus soliciting a pervasive intervention of the regulator (see Saule T. Omarova, "The New Crisis for The New Century: Some Observations on the "Big Picture" Lessons of the Global Financial Crisis of 2008”, North Carolina Banking Institute Journal 2009, 161; and Mads Andenas/Iris H-Y Chiu, The Foundations and Future of Financial Regulation, 2013 , p. 135, according to whom "the notion of investor protection is infused with wider 
2.2. Art. 24, para. 9, of MiFID II distinctly shows both of the above-mentioned functions laying down the requirements inducements have to comply with. On the one hand, it prescribes that all the inducements collected must "not impair compliance with the investment firm's duty to act honestly, fairly and professionally in accordance with the best interest of its clients" (let. $b$ ) - redundantly evoking the close link between inducements and conflict of interest regulation. Yet, at the same time, it adds that inducement schemes must also be "designed to enhance the quality" of the service provided to the client (let. a).

This latter disposition clearly goes beyond pure a conflict of interest dynamic. Theoretically, once an inducement is proved not to impair the best interest of the client, nothing more should be demanded from the distributor. ${ }^{10}$ Nevertheless, the 'quality-enhancement' requirement of art. 24, para. 9, let. a, MiFID II 'selects' also some specific features of investment services considered by the European regulator more suitable to protect investors' confidence and capital markets soundness, allowing the collection of inducements only under those specific circumstances. By doing so, financial intermediaries are 'nudged' to provide investment services compliant with those features (otherwise they cannot be remunerated for the services they provide).

\section{MiFID II Inducement Regulation}

Such a 'quality-enhancement' requirement is further specified by art.11, para. 2, of the Commission Delegated Directive (EU) 2017/593 ('Delegated Directive'), which distinguishes between investment advice and the other merely executive - investment services.

In particular, as to investment advice, the distributor shall guarantee either: (a) "access to a wide range of suitable financial instruments including an appropri-

financial stability concerns", requiring "greater regulatory paternalism in both the wholesale and retail sectors"). At the same time, it is now well acknowledged that the fiduciary nature of every investment relationship is better secured by an ex ante enforcement strategy rather than by an ex post civil liability of the advisor (see Andrea Perrone, "Servizi d'investimento e regole di comportamento. Dalla trasparenza alla fiducia", Banca borsa e titoli di credito 2015, 126).

10 According to Perrone (fn. 2), 138, the attempt to explain art. 24, para. 9, let. a, MiFID II in terms of conflict of interests is misleading. Indeed, either the conflict does not exist, making such rule useless; either the conflict does actually exist, turning art. 24 MiFID II into a questionable 'price' for unlawful conducts. See also Veerle Colaert, MiFID II in Relation to Other Investor Protection Regulation: Picking Up the Crumbs of a Piecemeal Approach, in: Danny Busch/Guido Ferrarini (ed.), Regulation of the EU financial markets - MiFID II and MiFIR, 2017, p. 596, highlighting the different provision brought by IDD for the distribution of insurance products. 
ate number of instruments from third party product providers having no close links with the investment firm" ('quasi-independent advice'); ${ }^{11}$ or $(b)$ a periodic assessment - "at least on an annual basis" - of "the continuing suitability of the financial instruments in which the client has invested", rather than periodic "advice about the suggested optimal asset allocation" ('periodic advice'). ${ }^{12}$

Instead, with reference to the provision of the other merely executive investment services, distributors can receive inducements only if they grant the access, (i) "at a competitive price", (ii) "to a wide range of financial instruments", together with (iii) "the provision of added-value tools" or other "periodic reports" that can help clients "to take investment decisions" and "to monitor, model and adjust the range of financial instruments" in which they have invested. ${ }^{13}$

Moreover, in assessing adherence to the requirements listed above, distributors should explicitly take into account whether all the commissions payed by the client are "proportional" to the quality of the investment service actually provided,$^{14}$ and whether the investment service offered entails a concrete and "tangible benefit" to him. ${ }^{15}$ In other words, this assessment should not be exclusively theoretical, but the financial intermediary must prove that the specific investment service offered is fully coherent with the actual best interest of the client. From this point of view, the mere provision of a 'quality-enhanced' investment service is not sufficient to justify the collection of inducements; rather, the distributor also has to judge whether the offered high-quality features of the investment service actually grant a "tangible benefit" to the client. ${ }^{16}$

\section{The Changing Market for Investment Services: The Rise of FinTech and the Role of Financial Advisors}

According to the 'public-policy function' of inducement regulation, the list of conditions laid down by the Delegated Directive tries to mirror very closely the recent evolution of financial intermediation.

11 Art. 11, para. 2, let. $a$, n. i, Delegated Directive.

12 Art. 11, para. 2, let. $a$, n. $i$, Delegated Directive.

13 Art. 11, para. 2, let. $a$, n. iii, Delegated Directive.

14 Art. 11, para. 2, let. $a$ and recital 22, Delegated Directive. Leaving no doubt on that, ESMA "Final Report - ESMA's Technical Advice to the Commission on MiFID II and MiFIR”, https://www.esma.europa.eu/document/technical-advice-commission-mifidii-and-mifir, last accessed 23 July 2019, 2014, 136 "makes clear that the inducements received should be proportional to the additional or higher quality services provided".

15 Art. 11, para. 2, let. $b$, Delegated Directive.

$16 \operatorname{ESMA}$ (fn. 14), 142; and Silverentand/Sprecher/Simons (fn. 1), p. 220. 
4.1 Thanks to the astonishing development of technology applied to financial activities ('FinTech'), algorithms and other forms of robo-advice can now provide investors with a diversified investment portfolio, widely coherent with their personal characteristics and needs ${ }^{17}$ Naturally - despite the new findings of behavioral economics ${ }^{18}$ and the most recent recommendation of ESMA ${ }^{19}$

17 As described by Paolo Sironi, FinTech Innovation, 2016, p. 29; and by Dominik Jung/ Florian Glaser/Willi Köpplin, "Robo-Advisory - Opportunities and Risks for the Future of Financial Advisory”, https://www.researchgate.net/publication/328390383 Robo-Advisory_Opportunities_and_Risks_for_the_Future_of_Financial_Advisory_ Recent_Findings_and_Practical_Cases, last accessed 23 July 2019, 2018, robo-advising usually starts with the client self-assessment of his "individual risk aversion and investment horizon", in order to select appropriate asset classes "according to each individual investor's profile" (on the self-evaluation process, see also the study of Michael Tertilt/Peter Scholz, "To Advise, or Not to Advise - How Robo-Advisors Evaluate the risk Preferences of Private Investors”, Journal of Wealth Management 2018, 70). On the other hand, as to portfolio composition, Michael Reher/Celine Sun, "Automated Financial Management: Diversification and Account Size Flexibility”, https://scholar.harvard. edu/files/mreher/files/reher-sun-2018.pdf, last accessed 23 July 2019, 2018; and Michael Reber/Celine Sun, "Robo Advisers and Mutual Fund Stickiness", https://scholar. harvard.edu/files/mreher/files/reher-sun.pdf, last accessed 23 July 2019, 2016 find that "automated financial management portfolios" are "significantly better diversified" than the traditional ones, highlight also that investments carried out by robo-advisers outperform on a risk adjusted basis the returns of professionally managed portfolios.

18 Since the contribution of Cass R. Sunstein/Christine Jolls/Richard H. Thaler, "A Behavioral Approach to Law and Economics”, Stanford Law Review 1998, 1471, and in spite of the homo oeconomicus theory, it is now widely acknowledged that "a plethora of psychological heuristics and biases steer the behavior of the investor" (Veerle Colaert, "Building Blocks of Investor Protection: All-embracing Regulation Tightens its Grip", Journal of European Consumer and Market Law 2017, 230). In particular - as incisively summarized by Gindici (fn. 7), p. 148 - "households are generally financially illiterate" and "tend to be overconfident"; indeed, "self-ignorance is one of the most important biases affecting retail investor financial behavior”. For similar conclusions, see also Robert Prentice, "Whither Securities Regulation? Some behavioral observations regarding proposals for its future”, Duke Law Journal 2002, 1397; Monica Gentile/Nadia Linciano/Paola Soccorso, "Financial Advice Seeking, Financial Knowledge and Overconfidence”, https://papers.ssrn.com/sol3/papers.cfm?abstract_id=2802589, last accessed 23 July 2019, 2016; Hans-Martin von Gaudecker, "How Does Households Portfolio Diversification Vary with Financial Literacy and Financial Advice?”, The Journal of Finance 2015, 489; Ronald J. Colombo, "Exposing the Myth of Homo Economicus", Harvard Journal of Law \& Public Policy 2009, 737; and Claire A. Hill/Erin Ann O'Hara, “A Cognitive Theory of Trust", Washington University Law Review 2006, 1717.

19 See ESMA, "Final Report - Guidelines on certain aspects of the MiFID II suitability requirements", https:/www.esma.europa.eu/sites/default/files/library/esma35-43869-_fr_on_guidelines_on_suitability.pdf, last accessed 23 July 2019, 2018, 43, demanding from investment firms "to ensure that the information collected about their clients is reliable and consistent", and clearly emphasizing that financial firms must adopt "me- 
FinTech advisors allow only a mere 'self-assessment' of the investor's profile. ${ }^{20}$ Therefore, the portfolio identified by the robo-advisor seems to actually represent "a more logical choice" of the investor, rather than a real "third-party recommendation". ${ }^{21}$ Moreover, investment allocation may result in one-time advice, seldom updated or improved with respect to both financial markets evolution and - especially - client's changing characteristics. ${ }^{22}$

chanisms to avoid [investor's] self-assessment”. At the same time, financial intermediaries should also adopt specific arrangements "to address the risk that clients may tend to overestimate their knowledge and experience". Indeed, such measures are "particularly important in the case of robo-advice, since the risk of overestimation by clients may result higher when they provide information through an automated (or semi-automated) system, especially in situations where very limited or no human interaction at all between clients and the firm's employees is foreseen". Similar recommendations govern also the provision of investment services in the U.S., where the Uniform Prudent Investment Act (adopted in 1992 by the American Law Institute's Third Restatement of the Law of Trusts) demands that investment advisors "make a reasonable effort to verify facts relevant to the investment and management of trust assets", as well to continuously monitor client's investments in order to ensure a proper alignment with his own 'profile'. For similar conclusion, see Melanie L. Fein, "Robo-Advisors: A Closer Look”, https://papers.ssrn.com/sol3/papers.cfm?abstract_id=2658701, last accessed 23 July 2019, 2015, 21, pointing out that "robo-advisor clients are essentially left on their own" also "to determine whether the robo-advisor's investment strategies are appropriate for their needs".

20 For this very reason (based on the assumption that robo-advisors may easily "ask questions that are over-generalized, ambiguous, misleading, or designed to fit [every investor] into the tool's predetermined options": FINRA/SEC, "Joint Investor Alert. Automated Investment Tools”, https://www.sec.gov/oiea/investor-alerts-bulletins/ autolistingtoolshtm.html, last accessed 23 July 2019, 2015, n. 3), ESMA (fn. 19), p. 36 demands from investment firms a specific attention in designing the suitability-assessment-test, due to the "limited human interaction". For similar conclusion, see also Sironi (fn. 17), p. 31.

21 Sironi (fn. 17), p. 31, but see also Fein (fn. 19), 12: "rather than characterize robo-advisors as providing personal investment advice, it is more accurate to describe them providing online tools for a client to use in determining the client's own risk tolerance and investment preferences and then enabling the client to subscribe to an investment strategy based on asset allocation formulas recommended for investors with similar preferences".

22 Actually, robo-advisors are often equipped with "algorithmic rebalancing" mechanisms that provide "stability of the portfolio weights" by "shifting investments among asset classes" in order to adjust the portfolio according to the changing market trends and the specific asset performances (Jung/Glaser/Klöppin (fn. 17), 10; but see also Jonathan W. Lam, "Robo-Advisors: A Portfolio Management Perspective", https://economics. yale.edu/sites/default/files/files/Undergraduate/Nominated\%20Senior\%20Essays/ 2015-16/Jonathan_Lam_Senior\%20Essay\%20Revised.pdf, last accessed 23 July 2019, 2016, 25 and Sironi (fn. 17), p. 30, though acknowledging that such rebalancing mechanisms are "constructed with fairly simplistic or straightforward optimization routines"). 
Yet, FinTech services may be extremely cheap if compared to 'traditional' investment advice and could thus represent a competitive alternative for smaller investors who cannot conveniently afford the costs of the traditional distribution channels. ${ }^{23}$ Hence, the wide support showed by regulators to "the development of mass-market automated advice models that have the potential to bridge the advice gap" that is excluding many retail investors from the market. $^{24}$

4.2 In such a scenario, the provision of simple one-time investment advice (the so-called 'spot advice') can hardly be justified to be in the actual best interest of the client. Indeed, this kind of investment service is to some extent comparable to FinTech advice, but much more expensive and limited to a narrower selec-

Nonetheless, robo-advisors often rely on incomplete or misleading information and most important - they "typically do not take into account that [investor's] financial goals may change” rapidly over time: see Fein (fn. 19), 6; and FINRA/SEC (fn. 20), n. 4 , arguing that a robo-advisor "may not assess all [the investor's] particular circumstances".

23 As reported by the European Commission, "Distribution systems of retail investment products across the European Union - Final Report”, https://ec.europa.eu/info/sites/ info/files/180425-retail-investment-products-distribution-systems_en.pdf, last accessed 23 July 2019, 2018, 137, "robo-advisors offer their services at comparatively lower prices than traditional wealth managers". In particular, the effective use of technology enables FinTech firms to provide high-quality investment advice with limited human interaction, while the investment in passive funds and ETFs assures comparable financial returns with lower commissions (see Sironi (fn. 17), p. 26; ESMA, "The impact of charges on mutual funds returns", https://www.esma.europa.eu/sites/default/files/ library/esma50-165-422_trv_-_vulnerabilities_-_investor_protection_corrected.pdf, last accessed 23 July 2019, 2017; and William A. Birdthistle, "The Fortunes and Foibles of Exchange-Traded Funds: A Positive Market Response to the Problems of Mutual Funds", Delaware Journal of Corporate Law 2008, 90. For a comprehensive data collection on robo-advisor fees and commissions, see Backend Benchmarking, "The Robo Report”, www.theroboreport.com, last accessed: 2 May 2019. From this perspective, "the significant difference" in costs and charges "highlights that the variance in pricing may enable increased affordability of robo-advisors to a wider population that has become more cost sensitive". In conclusion, "robo-advisors seems to possess the potential to achieve what discount brokers did forty years ago and further downshift the costs and complexities of the investment experience” (Sironi (fn. 17), p. 41).

24 FCA, "Financial Advice Market Review - Final Report", https://www.fca.org.uk/ publication/corporate/famr-final-report.pdf, last accessed 23 July 2019, 2016; but see also European Commission, "Action Plan on Building a Capital Markets Union”, https://eur-lex.europa.eu/legal-content/EN/TXT/?uri=CELEX:52015DC0468, last accessed 23 July 2019, 2015, 19, emphasizing that "the transition to online distribution of investment products and the emergence of new fintech solutions present an opportunity to develop further advisory services and 'open access' online distribution platforms". On the regulatory issue, see Tom Baker/Benedict G. C. Dellaert, "Regulating Robo Advice Across the Financial Services Industry”, Iowa Law Review 2018, 713. 
tion of investment products; rather, it seems to represent a pure rent-seeking that comes with the well-established position of the distributor. ${ }^{25}$

From this point of view, spot advice can no longer be deemed to enhance the quality of the service offered by the distributor, and therefore inducements cannot be lawfully collected for the provision of such an advice. This conclusion is probably one of the most remarkable innovations brought by MiFID II, whereas the former discipline explicitly stated that every time an "investment firm provides investment advice or general recommendations", then such advice "should be considered as having met the condition of being designed to enhance the quality of the service". ${ }^{26}$

Against this conclusion it cannot be argued that market dynamics are supposed to expel by themselves such practices, if really detrimental to investors. The lack of adequate transparency on the overall costs, the usually vague and fading contents of the services offered, as well as the difficulties traditionally experienced by retail investors in appraising the quality of the advice received, all tend to make competition among distributors less effective. ${ }^{27}$

4.3 On the other hand, it is now fully acknowledged the role that professional advisors can play not only in the early assessment of clients' profile or in the starting selection of investment products, but also (and, perhaps, mostly) in the on-going management of the portfolio. ${ }^{28}$ Indeed, even a suitable investment

25 See, for example, the 'mutual fund stickiness paradox' discovered by Reher/Sun, Robo Advisers and Mutual Fund Stickiness (fn. 17), 15; ESMA (fn. 23), 8.

26 CESR, "Inducements under MiFID I", https://www.esma.europa.eu/sites/default/files/ library/2015/11/07_228b.pdf, last accessed 23 July 2019, 2007, recommendation n. 5. See also Recital 39 of Directive 2004/39/EC ('MiFID I implementing Directive').

27 For example, Karel Lannoo, "Funds, fees and performance", https://www.ceps.eu/wpcontent/uploads/2018/07/KL_FeesAndFunds.pdf, last accessed 23 July 2019, 2007, 2018, 2 points out that "comparing and interpreting fees across providers and products is very difficult, even for a well-informed investor". Indeed, "information provided to clients is not transparent", nor "standardised across countries"; even "digitalisation or robo-advice will not necessarily change this assessment. Even if it may make it easier to compare products, it will not reduce the sheer complexity of the supply". On the other hand, ESMA (fn. 23), 6 notices also that, "despite the impact of fees and charges on the net outcome to investors, these costs do not seem to be reflected in investor choices, given that aggregate net flows to EU fund shares evidently react hardly at all to management fees, and even less so to cost-adjusted net returns”. For similar results, see also Reher/Sun, Robo Advisers and Mutual Fund Stickiness (fn. 17), 15, emphasizing that probably because investors "place greater value on the trustworthiness" - they "do not seem to switch to robo-advisory" even if robo-advisors "outperform their current fund manager".

28 See Consob, "Report on Financial Investments of Italian Households - Behavioral Attitudes and Approaches”, http://www.consob.it/documents/46180/46181/rf2018.pdf/ 
may easily turn into a severe loss if not properly monitored, and investors may also suffer from the missed opportunity of making additional earnings on their investments by promptly selling their assets. Hence, it is convenient to periodically monitor the portfolio optimal asset allocation, which may lead to realize revenues at the appropriate time and to efficiently govern market volatility (as well as investors' anxieties). ${ }^{29}$ In addition, even the changing characteristics and needs of the client may demand a periodic update of the investment portfolio, in order to keep it fully compliant with the 'suitability test' required by art. 25 , para. 2, MiFID II. ${ }^{30}$

Most importantly, financial advisors can also play a crucial role in protecting consumers and preserving financial stability, providing households with 'integrated' financial assistance that may involve - besides investment advice - a proper debt reduction pattern, an adequate insurance plan, as well as private pension and retirement arrangements. ${ }^{31}$

276cd341-adfe-449c-b8df-c6205d82de27, last accessed 23 July 2019, 2018, noting that many investors "do not track the performance of their investments"; and Giudici (fn. 7), p. 149, according to whom "households tend to maintain fixed beliefs about the fundamental value of shares in the face of market price movements ... They are therefore extremely vulnerable to the disposition effect and thus to 'momentum behavior', which lead them to ride losses and quickly realize gains".

29 On the automated portfolio rebalances algorithms, see supra fn. 22. In particular - compared to FinTech investment services - “a human adviser can offer personalized investment guidance, and encourage investors to save more, diversify, and engage in less speculative trading". Moreover, "human adviser can be available to the investor at crucial times such as during market volatility when investors are most likely to panic and make investment mistakes” (Fein (fn. 19), 5, quoting Robert Litan/Hal Singer, “Good Intentions Gone Wrong: The Yet-To-Be-Recognized Costs of the Department Of Labor's Proposed Fiduciary Rule", 2015, 2, according to whom "an email or text message in the fall of 2008, for example, would not have sufficed to keep millions of panicked savers from selling, with devastating consequences for their nest eggs").

30 Fein (fn. 19), 6; FINRA/SEC (fn. 20), n. 4.

31 The importance of professional and comprehensive financial planning is well known, especially because many investors show "a low or very low overall attitude towards budget monitoring” (Consob (fn. 28), 10). Indeed - as for investment products - also insurance contracts are "extremely complicated" and "quite variable". Moreover, "individuals are subject to various well-established heuristics and biases when it comes to making insurance decision"; for instance, "consumers routinely buy insurance they should rationally avoid" and "avoid or under-consume insurance they should rationally want". In this perspective, professional advisors "could help reverse these tendencies, particularly when consumer biases would otherwise lead to insufficient insurance demand" (Daniel Schwarcz/Peter Siegelman, Insurance agents in the twenty-first century. The problem of biased advice, in: Daniel Schwarcz/Peter Siegelman (ed.), Research Handbook on the Economics of Insurance Law, 2015, p. 36; see also Tom Baker/Peter Siegelman, "You Want Insurance with That? Using Behavioral Economics to Protect 


\section{The Architecture of MiFID II Investment Services: The Perspective of Inducement Regulation}

The new inducement regulation brought by MiFID II widely reflects all of these new market features.

First of all - as noted by the European Commission ${ }^{32}$ - FinTech may effectively address the advice gap experienced by smaller investors. Because of this, the Delegated Directive allows the collection of inducements even outside the provision of investment advice (consistently with the business model of many FinTech firms). ${ }^{33}$ At the same time, 'spot advice' - which poorly performed in the past - is indirectly banned by the quality-enhancement provision set forth in art. 24 MiFID II. ${ }^{34}$ Lastly, the acknowledged importance of on-going monitoring clearly opens up the collection of inducements linked to the provision of 'periodic advice'. ${ }^{35}$

Additionally, in line with the traditional function of inducement regulation, MiFID II also addresses the problems stemming from the conflict of interests between investment firms and their clients introducing - besides the general duty not to act against client's best interest - independent and 'quasi-independent' advice. ${ }^{36}$

Consumers from Add-On Insurance Products”, Connetticut Insurance Law Journal 2013 , 1). Naturally, similar conclusion could also be drawn for retirement savings' management. Indeed - since "national pensions systems are challenged by demographic and labor market changes", as well as by "pressure on national budgets" - improving "consumer information and protection in voluntary personal retirement savings is necessary to enhance consumers' confidence" in the market (EIOPA, "Advice on the development of an EU Single Market for personal pension products”, https://www.eiopa.europa.eu/ content/eiopas-advice-development-eu-single-market-personal-pension-productsppp_en, last accessed 23 July 2019, 2016, 9). In this perspective, financial advice may help many individuals "to make the best decisions when purchasing financial products or services" (p. 42). Moreover, "distributors can also play a crucial ongoing role, aiding consumers in assessing their retirement provisions over time, and helping trigger changes in the consumers' allocation of resources" (p. 39). In this perspective, the progressive rise of universal banks and financial conglomerates providing heterogeneous financial services strongly encourages the adoption of full-fledged financial support, though dramatically increasing the risk of new conflict of interests (on this issue, among others, Alan D. Morrison, Universal Banking, in: Allen N. Berger/Philip Molyneux/John O. S. Wilson (ed.), The Oxford Handbook of Banking, 2017, p. 113).

32 See the European Commission (fn. 19), 19.

33 See supra section 3 and art. 11, para. 2, let. a, n. iii, Delegated Directive.

34 See supra section 4.2.

35 See art. 11, Delegated Directive.

36 Respectively, art. 24, para. 7, MiFID II and art. 11, para. 2, let. a, n. $i$, Delegated Directive. 


\section{Fee-Only Independent Advice}

To this latter end, independent investment advice is certainly meant by the EU regulator to perform an essential role in financial intermediation, "not least given the higher levels of trust and the consequent potential for stronger market engagement associated with fee-based advice" ${ }^{37}$ Indeed, the radical ban of inducements and the assessment of a wide range of third-party financial instruments are supposed to remove the major source of conflict of interests that may stem from commission-based advice provided by a single or multi-tied agent (and, a fortiori, from the placement of proprietary products).

Undoubtedly, the provision of independent advice removes the risk that both issuers' activities and distributors' assessments may be biased by the collection of commissions. However, a fee-only compensation scheme may give rise to new sources for conflicts of interest between investment firms and their clients. ${ }^{38}$ Since competition among independent advisors will mostly depend on their relative performances (id est: on the revenues actually earned by their clients), they may be incentivized to 'waive' or 'stress' the suitability requirements in order to carry out riskier activities and thus foster - at least in the short term - the expected gains demanded by the investors. ${ }^{39}$

6.1 Anyway, the European market is not yet mature enough for fee-only independent advice. The current commission-based system is inherently opaque and most investors lack sufficient awareness about the costs of the service received: a significative number of clients, indeed, do not know how their advi-

37 Moloney (fn. 2), p. 257; Financial Services Authority (fn. 1), 35; as well as the Authors cited supra in section 2.

38 See, for example, Financial Services Authority, "Risks to customers from financial incentives - Final guidance”, https://www.fca.org.uk/publication/finalised-guidance/fsafg13-01.pdf, last accessed 23 July 2019, 2013; EIOPA, "Final Report - Technical Advice on Possible Delegated Acts Concerning the Insurance Distribution Directive”, https:// www.eiopa.europa.eu/content/eiopa\% E2\% 80\% 99s-technical-advice-possibledelegated-acts-concerning-insurance-distribution-directive_en, last accessed 23 July 2019, 2017, 63; and Roman Inderst/Marco Ottaviani, "Competition through Commissions and Kickbacks", The American Economic Review 2012, 788.

39 See Moloney (fn. 4), p. 795, highlighting that "the independent advice channel" tend to "produce riskier investment recommendation"; Financial Services Authority (fn. 38), 14, targeting - among others bad practices - those compensation "schemes where high performance can trigger significant additional incentives, both monetary and non-monetary". Such problems, indeed, can arise in many different areas: see for example the accurate analysis of Ronald J. Gilson /Jeffrey N. Gordon, "The Agency Costs of Agency Capitalism: Activist Investors and the Revaluation of Governance Rights", Columbia Law Review 2013, 863, discussing the incentives of mutual funds to actively engage the management of the companies in which they have invested. 
sors are compensated and some of them even believe investment advice is free, thus reducing their willingness to pay for such a service. ${ }^{40} \mathrm{Clearly}$, this kind of prejudice and misrepresentations greatly hinders the spread of independent advice, since an investment firm would have to move 'against the market' in the attempt to set a new standard. ${ }^{41}$

With the purpose to overcome such biases, MiFID II conveniently strengthens the disclosure requirements over the features and costs of the investment advice provided by the investment firms. ${ }^{42}$ In particular, art. 11, para. 5, of the Delegated Directive and art. 50, para. 2, of the Commission Delegated Regulation (EU) 2017/565 ('Delegated Regulation') state that investment firms must aggregate and disclose - both on an ex ante and expost basis - all the costs and

40 See ESMA, "Technical Advice to the Commission on the impact of the inducements and costs and charges disclosure requirements under MiFID II", https://www.esma.europa. $\mathrm{eu} /$ document/technical-advice-impact-inducements-and-costs-and-charges-disclosurerequirements-under, last accessed 25 November 2020, 2020. Indeed, the "willingness to pay for advice is generally low, and even lower when an investor becomes aware of the possible conflict of interests his advisor faces" (Lannoo (fn. 27), 3). More often though, "investors have little or no idea about how advisors can get paid", and unless they "are told what affects the amount of fees they pay, they are unlikely to reach an accurate conclusion on their own". In a recent survey, Consob (fn. 28), 9 reported that "advisees do not seem aware of the characteristics of the service received": indeed, "almost $80 \%$ of those relying on professional advice either state the service is free or don't know whether it is compensated". For similar conclusions, among others, see also ESMA (fn. 14), 135; Financial Services Authority (fn. 1), 55; Investor Education Fund, "Investor Behavior and Benefits: Advisor Relationship and Decision-Making Study, 2012, 33; and Moloney (fn. 2), p. 271.

41 According to Consob (fn. 28), 9, more than $50 \%$ of the households interviewed are not willing to pay for investment advice, even though willingness to pay "rises with formal education and financial knowledge" (see also the Authors cited supra fn. 18). Similarly, Lannoo/Casey (fn. 2), p. 122 highlight "the difficulties associated with the cultural shift that would necessarily accompany any prohibition of commission arrangements".

42 From this perspective, "MiFID II policy effort is to nudge investors, especially retail investors, towards fee-only advisory services" (Giudici (fn. 7), p. 162). Coherently, art. 24, para. 4, MiFID II requires investment firms to inform clients whether "the advice is provided on an independent basis", and whether it "is based on a broad or on a more restricted analysis of different types of financial instruments", emphasizing the existence of possible "links" with the product provider that could impair the advisor's assessment. Investment firms must also disclose whether the service provided consist in "a periodic assessment of the suitability of the financial instruments recommended" (let. a). On the other hand, investment firms must provide clients with "appropriate information" on "costs" and "charges" related to the provision of the investment service offered, including all the "information relating to both investment and ancillary services", like "the cost of advice ... the cost of the financial instrument recommended or marketed to the client and how the client may pay for it, also encompassing any third-party payments" (let. c). 
charges directly or indirectly associated with the provision of an investment service. In addition, in order to increase investors' awareness and to promote competition among advisors, all the inducements received "shall be itemized separately and the aggregated costs and charges shall be totaled and expressed both as a cash amount and as a percentage". ${ }^{43}$

The efficacy of such measures will be carefully assessed in the near future. ${ }^{44}$ Notwithstanding its obvious potential, the ability of this new transparency regulation in shaping the European financial intermediation system depends also on the investors' capacity - still widely challenged - to appraise contents and features of the advice received. ${ }^{45}$

43 See ESMA (fn. 40). As emphasized by art. 24, para. 4(2), MiFID II, "all this information must be "provided to the client on a regular basis, at least annually, during the life of the investment" and must "be aggregated to allow the client to understand the overall cost as well as the cumulative effect on return of the investment", but "an itemised breakdown" has to be provided as well. On the importance of such requirements, see ESMA (fn. 40), proposing to strengthen such a disclosure discipline; Investor Education Fund (fn. 40), 33, suggesting that both cash "amount and percentages are needed to meet the needs of investors"; Andrea Perrone, “A Brave New World? Investment Services and Investor Protection”, Working paper, 2019, para. 5, noting that "a disclosure-based rule explicitly aimed at preventing the intermediary from using framing techniques to reduce the service's perceptible cost is a highly effective instrument against rent-seeking in favor of a more prominent competitive environment”; Colaert (fn. 18), 233; and Lannoo/Casey (fn. 2), p. 116.

44 Lannoo (fn. 27), 3 and ESMA (fn. 40).

45 According to Consob (fn. 28), 9, only 5\% of retail investors pay attention "to the overall costs of the investment service received", and "information about past performances seems to be more salient than costs disclosure”. Moreover, retail investors also experience serious difficulties "in identifying valuable features of their financial advisors", and "a proportion ranging between $40 \%$ and about $70 \%$ of the interviewees ... has no opinion at all". Similarly - as reported by Investor Education Fund (fn. 40), 32 - "even when the full range of fees and what affects them is identified", it may be "difficult for investors to assess the implications of what they have learned". In particular, "potential conflict of interest" are highly difficult to consider, "since they are counter to the high level of trust that underpins their advisor relationship"; indeed, "having been informed about these various commissions and fees, half of investors could not form a view about conflict of interest". On this issue, see also ESMA (fn. 40), para. 59 and 75; Armour/ Awrey et al. (fn. 2), p. 241; Roman Inderst/Marco Ottaviani, "Regulating Financial Advice”, European Business Organization Law Review 2012, 237; and Busch (fn. 3), 355, wondering "how effective this information obligation is", since household "will often not read the information due to its sheer quantity" and complexity. 


\section{The 'Quasi-Independent Advice' and the 'Open-Architecture' Requirement}

In order to work around the difficulties of shifting to a fee-only intermediation system, the EU regulator has also introduced a 'quasi-independent' investment advice.

As pointed out by art. 11, para. 2, let. $a$, n. $i$, of the Delegated Directive, investment firms can receive inducements if they supply clients with access "to a wide range of suitable financial instruments including an appropriate number of instruments from third party product providers having no close links with the investment firm". The possibility to invest in many financial products is an expensive solution for advisors, since they have to commit time, resources and effort to acquire information and monitor all the investment products distributed ${ }^{46}$ in this respect, such a waiver of the inducement ban seems to be well grounded. At the same time - although the collection of inducement becomes licit - the independence of the advisor is still preserved by the variety of the 'sources' from which commissions can actually come. Moreover, the provision of a wide range of suitable financial instruments may broaden the investment choices available to clients, support portfolio diversification, and encourage the development of a more integrated European capital market.

7.1 Even though quasi-independent advice seems to embody the genuine rationale that inspired MiFID II regulation on investment services, it may be questioned whether it could actually represent an effective alternative for the European financial system.

Product governance requirements, indeed, greatly increase the coordination costs between manufacturers and their distributors. ${ }^{47}$ These latter have to "take

46 It should be also emphasized that art. 24, para. 2(2), MiFID II explicitly requires investment firms to fully "understand the financial instruments they offer or recommend", obtaining from manufacturer all the information needed "to gain the necessary understanding and knowledge of the products they intend to recommend or sell in order to ensure that these products will be distributed in accordance with the needs, characteristics and objectives of the identified target market" (art. 10, para. 2(2) and (3), Delegated Directive; for a critical evaluation of such provision, see Colaert (fn. 18), 229 and 237). In addition, investment firms must also "review the investment products they offer or recommend and the services they provide on a regular basis, taking into account any event that could materially affect the potential risk to the identified target market" (art. 10, para. 5, Delegated Directive).

47 See ESMA (fn. 40), para. 56 and Danny Busch, Product Governance and Product Intervention under MiFID II/MiFIR, in: Danny Busch/Guido Ferrarini (ed.), Regulation of the EU financial markets: MiFID II and MiFIR, 2017, p. 123. Highlighting the "heavy burden" placed against distributors, Colaert (fn. 18), 229 notes that "although increased interaction between product providers and distributors should in principle be regarded 
all reasonable steps" to obtain "from the manufacturer" the information needed "to gain the necessary understanding and knowledge of the products" they sell. ${ }^{48}$ Above all, distributors also have to fix and adjust their distribution strategies in order to make them compliant with the target market pre-identified by the manufacturer, assuring that all the products they offer "are compatible with the needs, characteristics, and objectives" of their clients. ${ }^{49}$ In addition, they must periodically assess "whether the product or service remains consistent" with the relevant target market and "whether the intended distribution strategy remains appropriate", promptly amending it when needed. ${ }^{50}$ All these costs critically affect procedures and organization of the investment firms, threatening to restrain their activity. ${ }^{51}$ For this very reason - since the EU financial markets are firmly controlled by distributors ${ }^{52}-$ such an increase in coordination costs will lead intermediaries to 'close' their architectures by selling, for the most part, products issued by firms belonging to the same financial conglomerate (who will ex ante design products fully compliant with the distribution policy of the whole group). ${ }^{53}$ Indeed, in a 'distribution-or-

as a positive evolution, it may be problematic that MiFID II places the responsibility of gathering missing product information upon the services provider". Indeed, "for smaller services providers this may prove quite a challenge" and "if they fail to meet this challenge, their only option may be to cease distribution of the product in question".

48 Art. 10, para. 2(2), Delegated Directive, as to MiFID manufacturers; art. 10, para. 2(3), Delegated Directive for non-MiFID product providers. See also Busch (fn. 47), p. 124 and Colaert (fn. 18), 229, 237.

49 Art. 10, para. 2(1), Delegated Directive; Busch (fn. 47), p. 132.

50 Art. 10, para. 5, Delegated Directive; Busch (fn. 47), p. 134.

51 Indeed, even though "selling products outside the target group is not absolutely forbidden", it "should not happen on a regular basis and the reason for the deviation should be clearly documented"; similarly, "selling products in the negative target market should be a rare occurrence and the justification for the deviation should be accordingly significant" (Colaert (fn. 18), 237; but see also ESMA, "Final Report - Guidelines on MiFID II product governance requirements”, https://www.esma.europa.eu/document/finalreport-guidelines-mifid-ii-product-governance-requirements, last accessed 23 July 2019, 2018, 46). From this perspective, a whole range of products may not be available anymore to certain categories of clients due to the possible mismatch between the 'target market' (especially the 'negative target market') set by the manufacturer and the distribution criteria developed by the advisor. For a similar conclusion, see also Cherednychenko (fn. 1), 418; and Perrone (fn. 43), para. 4, highlighting "the opportunity cost" brought by product governance provisions "for the possible reduction in the areas of innovation".

52 Moloney (fn. 2), p. 262.

$53 \mathrm{Krng}$ (fn. 2), 128 also suggests that advisors usually do "not understand alternative products sufficiently to provide competent advice about" them. For this reason, many investment firms conveniently instruct their advisor not to recommend or sell investment product they do not fully understand. 
iented' system, product regulation may create a 'monopolistic relationship' between manufacturers and their distributors, where the latter may demand the design of 'tailor made' investment products. ${ }^{54}$

From this perspective, because of the 'open architecture' implicitly required by art. 11, para. 2, let. $a$, n. $i$, of the Delegated Directive, quasi-independent advice - in a market controlled by distributors - seems to represent an inefficient alternative doomed to remain a dead letter.

\section{The New Market for Investment Services: Between FinTech...}

Contingent on the results of the new transparency regulation (art. 24, para. 4, MiFID II), the provision of investment services will probably develop, at least in the near future, within two opposites 'poles': FinTech and periodic advice. ${ }^{55}$

8.1 As already mentioned, the provision of mere 'spot advice' is de facto banned by the Delegated Directive. ${ }^{56}$ No longer profitable for distributors, who cannot receive inducements, the corresponding demand for investments advice will be probably taken up by FinTech firms, as they are able to offer a comparable service at a significantly lower cost.

Accordingly, the Delegated Directive allows the collection of inducements even outside the strict provision of investment advice, ${ }^{57}$ so as to encourage the development of FinTech services, while simultaneously reducing the risks associated with such an activity (once again, highlighting the 'public policy' function performed by inducement regulation). In particular, as in the case of 'quasi-independent advice' ${ }^{58}$ distributors shall provide clients with access to a wide range of third-party financial products, thus widening investment choices and preventing conflicts of interest. Indeed, thanks to the lighter approach involved in the provision of merely executive investment services, investment firms can distribute third-party products in an easier (and more profitable) way to their clients.

54 Colaert (fn. 18), 240, noting that "product governance rules introduce a kind of 'knowyour-customer' at group level: as from the product design phase the profile of a target group of clients should be taken into account so that the product can be geared toward that target group"; Busch (fn. 47), p. 125.

55 Supra sections 4 and 5.

56 See supra section 4.2 and ESMA (fn. 14), 136, highlighting that MiFID II "has not replicated the content of recital 39 of the MiFID implementing directive which identified compliance with the quality enhancement criterion in cases in which simple investment advice or general recommendations were provided".

57 Art. 11, par, 2, let. a, n. iii, Delegated Directive. See supra section 3.

58 See supra section 7. 
At the same time - closely restating the general incipit of art. 11, para. 2, let. a, of the Delegated Directive ${ }^{59}$ - all the investment products shall be offered at a "competitive price". By imposing a strict proportionality between the service received and the commissions paid by the investors, MiFID II attempts to mitigate the risk that investment firms could unfairly benefit from the privileges that may come with their market position (rent-seeking). ${ }^{60}$

Finally, distributors shall also provide "added-value tools" or other "periodic reports" that help clients "to take investment decisions" and "to monitor, model and adjust the range of financial instruments" in which they have invested. In this respect, because clients are not aided by their advisor in the ongoing management of the investments made (as in the case of spot advice), the EU regulator - maybe a little naively ${ }^{61}$ - tries to provide all the necessary tools to enable them to manage their own portfolio independently.

8.2 Having said that, some FinTech start-ups seem to prefer a fee-only business model, based on high-tech robo-advice, often shaped like a 'standardized portfolio management' and mainly focused on ETFs and other passive funds. Indeed, such investment funds - which have far lower management costs but still notable returns - may be, for these very reasons, unwilling to agree upon any inducement compensation scheme. Instead, this provision of the Delegated Directive could represent an effective alternative for FinTech services offered by incumbent distributors (especially by banks), which already have strong relationships with the major asset managers. ${ }^{62}$

8.3 Lastly, it may be worth noting that in this new high-tech environment product governance could represent an effective protection for investors. Indeed, by regulating the 'manufacturing process', product governance distinctly signals the target market for which every investment product is designed, ${ }^{63}$ standardizing the possible outcomes of investment decisions and - to a certain extent - the distribution policy itself. At the same time, by requiring that "the strategy for distribution of the financial instruments is compatible with the identified target market", product governance tries to prevent (at least) the most striking cases of mis-selling even in a fully-automated advising process,

59 See supra section 3.

60 On this issue, see supra section 4.2.

61 See supra fn. 19, as well as the Authors cited supra fn. 9.

62 Extensively, see Fein (fn. 19), 12.

63 Even though product governance applies only to those manufacturers that are also "investment firms" (art. 1 MiFID II), "when offering or recommending financial instruments [issued] by entities that are not subject" to MiFID II, investment firms themselves have to "determine the target market for the respective financial instrument, even if the target market was not defined by the manufacturer" (art. 10, para. 1 (2)(3), Delegated Directive). On this issue, see Busch (fn. 47), p. 124. 
where the traditional suitability test seems to represent an incomplete solution. ${ }^{64}$ From this point of view, product governance finds its own natural environment in the FinTech industry rather than in the traditional intermediation channel, dominated by large banks and regulated by conduct of business rules. ${ }^{65}$

\section{9. ...And 'Periodic Advice' (Follows)}

On the other hand, traditional investment advice will probably shift towards 'periodic advice', the only effective alternative left by the Delegated Directive in order to keep collecting inducements.

In this regard, it is important to understand that, from a public-policy perspective, periodic advice is better able to meet the aforesaid need that investors be 'guided' all along their investment relationship with the distributor. Indeed by monitoring over time the suitability of the client's portfolio, as well as the abidance of a correct asset allocation - periodic advice can effectively encompass (in a sense) even the on-going management of the investments carried out.

Not surprisingly - in line with this reasoning - MiFID II explicitly enlarges the definition of investment advice to encompass all trading recommendations, "including whether or not to buy, hold or sell an investment" ${ }^{66}$ This provision clearly represents a valuable protection for investors, even though - at least in the provision of periodic advice - it could involve more severe liability for the investment firm.

From this perspective, periodic advice seems to resemble a rudimentary form of portfolio management, although it still preserves a more 'static' nature and a 'lighter' approach. More precisely, while the portfolio management service demands, in a strict sense, an on-going management of the portfolio in order to continuously monitor the optimal asset allocation, investment advice requires only a periodic assessment of the investment suitability (id est, an assessment that occurs on a regular basis, at regular periods of time). From this perspec-

64 Art. 24, para. 2, MiFID II; about the robo-advice suitability-test, see supra section 4.1. For similar conclusion, see Perrone (fn. 43), section 4.

65 As noted by Perrone (fn. 43), section 8, "the traditional allocation of the customer relationship to the distributor could be replaced by a combination of 'certified' products issued by manufacturers and distribution provided by electronic platforms".

66 Recital n. 87 and art. 9 of the Delegated Regulation; but see also ESMA (fn. 20), 50 and, for the previous regime, CESR, "Q\&A - Understanding the definition of advice under MiFID”, https://www.esma.europa.eu/sites/default/files/library/2015/11/10_293.pdf, last accessed 23 July 2019, 2010, 9, para. 31. 
tive, these two investment services seem to differ from each other not just as to their specific features and contents, but more importantly as to the 'intensity' with which such an assessment must be carried out by the distributor.

\section{The 'Advice Gap' and the Need for a Broader Interpretation of MiFID II Inducement Provisions}

The expected shift toward periodic advice will inevitably increase the costs associated with the provision of investment advice itself.

Accordingly, the new disclosure requirements over costs and features will have to play a key role in order to safeguard the efficiency of European capital markets. ${ }^{67}$ In particular, it is important that transparency, which stirs competition among distributors, would represent an effective deterrent for misbehavior, so as to guarantee that the expected growth of commissions would be linked to a corresponding increase in the quality and the actual value of the advice. From this perspective, FinTech can play an important role too, engaging financial firms in a vigorous competition and challenging most of the incumbents' rent-seeking practices. ${ }^{68}$ At the same time, it is also important to adequately calibrate such disclosure requirements, so as not to result in a 'race to the bottom' on the quality of the investment products. In fact, once the costs of advice come into the spotlight, there is a concrete risk that distributors may attempt to overtake their competitors by offering (at lower cost) poor-quality investment products and services. They may be able to do this because the 'quality' of such services may be much harder to asses and more difficult to perceive than costs $;^{69}$ similarly, while costs must be disclosed annually, the assessment of an investment product may require a much longer time horizon.

Anyway, as long as the expected rise in costs is effectively associated with the provision of higher-quality investment advice, fully coherent with the actual interest of the clients, there is little room for concern. The improvements in the protection of clients, the strengthening of investors' trust in financial markets, as well as the increase of investment returns due to a periodic assessment of the portfolio, all seem to outweigh the costs that will probably stem from the new regulation of inducements. ${ }^{70}$

67 See supra section 6.1 and art. 24, para. 4, MiFID II.

68 See Europe Economics, "Retail Distribution Review - Post Implementation Review", https://www.fca.org.uk/publication/research/rdr-post-implementation-review-europeeconomics.pdf, last accessed 23 July 2019, 2014, 62.

69 See supra fn. 45.

70 For similar conclusions on the product governance regime, see Perrone (fn. 43), section 4; Busch (fn. 47), p. 146; and Colaert (fn. 18), 241. 
10.1 Nevertheless, this shift towards periodic advice could also lead to other unintended consequences.

The actual advantages of high-quality investment advice inevitably shrink as the 'size' of the invested assets decreases, until the costs associated with the provision of periodic advice are no longer justified by the corresponding benefits. As a result, smaller investors, who have limited assets at their disposal, might be excluded from access to any kind of investment advice. ${ }^{71}$ Disproportionate in costs for clients and perhaps not even profitable for distributors themselves, in these situations, investment advice will be inevitably replaced by

71 Such an outcome is particularly worrying, given that " 80 per cent of retail investor in the EU use advice to inform their purchase decision" [Grundmann/Hacker (fn. 3), p. 193, reporting the decision of Lloyds banking group "to restrict investment advice ... to retail consumer investing more than £ 100.000"; see also Nick Chater/Steffen Huck/Roman Inderst, "Consumer Decision-Making in Retail Investment Services: A Behavioral Economics Perspective - Final Report to the European Commission”, https://www.wiwi.uni-frankfurt.de/fileadmin/user_upload/dateien_abteilungen/abt_ fin/Dokumente/PDFs/Allgemeine_Dokumente/Inderst_Downloads/POLICY_ PAPERS_and_POLICY_RELATED_REPORTS/consumer_decision-making_in_ retail_investment_services_-_final_report_en.pdf, last accessed 23 July 2019, 2010, 385; Consob (fn. 28), 8; Michael S. Finke/Sandra J. Huston/Danielle D. Winchester, "Financial Advice: Who Pays?”, Journal of Financial Counseling \& Planning 2011, 18; and Andreas Hackethal/Michael Haliassos/Tullio Jappelli, "Financial Advisors: A Case of Babysitters?”, Journal of Banking \& Finance 2012, 509]. According to Krug (fn. 2), 138 , the problem is twofold: on one hand, many retail investors "may simply deem the cost" of advice "prohibitive or, in any event, not worth any resulting benefit, given their often-limited investment assets". On the other hand, "many investment advisers do not accept retail investors as clients, given the advisers' requirements that clients have a threshold amount of assets as to which they are seeking advice” (p. 125). Form a different perspective, the Financial Conduct Authority, "Post-implementation review of the Retail Distribution Review - Phase 1", https://www.fca.org.uk/publication/ research/post-implementation-review-rdr-phase-1.pdf, last accessed 23 July 2019, 2014, 12 suggests that "there is little evidence that the availability of advice has reduced significantly" because of the RDR; indeed, "by revealing the true cost of advice", these new rules have "led some consumers to consider the extent to which the advice they receive represents value for money, and in some cases conclude it does not" (see also Towers Watson, “Advice Gap Analysis: Report to FCA”, https://www.fca.org.uk/ publication/research/advice-gap-analysis-report.pdf, last accessed 23 July 2019, 2014, 8). Anyway - as noted by Europe Economics (fn. 68), 62 - it is likely that "some of these consumers who are unwilling to pay for advice might instead pay for a cheaper, simplified advice". Therefore, investment firms should be enabled "to develop 'simplified advice' which could be both cost-reflective and affordable to the mass market, meeting the needs of consumers with lower levels of investable wealth and less complex investment needs". 
FinTech, thus worsening the problem of 'advice-gap' for smaller investors (at least in its traditional appearance). ${ }^{72}$

On the other hand, it could also be questioned whether investment firms could even lawfully recommend periodic advice to such small retail investors; indeed, inducements must not "directly benefit" the distributor "without tangible benefit to the relevant client" ${ }^{\text {"3 }}$ and - in any case - they cannot be accepted "if the provision of relevant services to the client is biased or distorted as a result" ${ }^{\prime 74}$. Therefore, it is doubtful that periodic advice - with its higher costs could bring a "tangible benefit" to such clients, so to be deemed in their actual best interest. ${ }^{75}$

10.2 While FinTech services - as already mentioned - could represent a cheaper but substantially comparable alternative to traditional investment spot advice, they may still give rise to serious concerns about investor protection.

It is well known that retail investors usually lack the appropriate financial knowledge to understand how investment products and capital markets actually work. ${ }^{76}$ In this respect - since financial education can represent only a partial solution ${ }^{77}$ - investors have traditionally sought professional advice in order to overcome such an asymmetry of information. ${ }^{78}$ For their part - at least, until now - FinTech firms have performed this task adequately. Yet, investors are also frequently prone to cognitive biases that may push them to "overvalue their competencies when self-rating their financial understanding", thus indu-

72 Such a view is widely shared among both scholars and regulators: see supra section 4.1 and, in particular, Europe Economics (fn. 68), 62, though waring that FinTech and roboadvisors are "not necessarily a panacea here". Indeed, whilst they "may likely be part of a simplified advice solution, there is also caution that, whilst cost-efficient, an algorithmic error could result in systemic advice problems".

73 Art. 11, para. 2, let. $b$, Delegated Directive.

74 So, the last period of art. 11, para. 2, Delegated Directive.

75 See supra section 3.

76 Among others, see Consob (fn. 28), 7; Gentile/Linciano/Soccorso (fn. 18), 26; and Maarten van Rooij/Annamaria Lusardi/RobAlessie, "Financial Literacy and Stock Market Participation”, Journal of Financial Economics 2011, 449.

77 Kendall Grant, "From Investor Education to Investor Protection: The Limits of Disclosure and the Way Forward", Banking \& Finance Law Review 2016, 239; Chater/ Huck/Inderst (fn. 71), 387; and Colaert (fn. 18), 232 and fn. 48: "even when the best performing indicators and KID was used, a large group of retail investors still did not succeed in drawing correct conclusions from the information provided". In conclusion, "even if consumers are well-informed, financial literacy does not always translate into good financial behavior”

78 Gentile/Linciano/Soccorso (fn. 18), 26 and 30; Giudici (fn. 7), p. 149; Investor Education Fund (fn. 40), 32; Perrone (fn. 9), 126. 
cing them to take disproportionate risks. ${ }^{79}$ Such cognitive biases clearly highlight the role that professional advisors actually play, even in the early stage of the relationship with their clients, by helping them to properly assess their own 'investment profile'. Recognizing this potential bias, the EU regulator explicitly demands that financial intermediaries "take reasonable steps and have appropriate tools to ensure that the information collected about their clients is reliable and consistent, without unduly relying on clients' self-assessment" ${ }^{80}$

Cleary, this latter, essential, function can hardly be performed by FinTech firms, which necessarily rely on clients' self-assessment. Moreover, the critical issues related to such a self-assessment can only be mitigated by a careful inquiry, fully compliant with all the best practices outlined by the EU regulator in order "to check the reliability, accuracy and consistency of information collected about clients". ${ }^{81}$ In this respect, the differences between FinTech services and traditional investment advice - even spot advice - are still significant, and the former cannot entirely replace the latter, despite the (formal) principle of "technological neutrality" envisaged by the European Commission.

Even more so, similar conclusions can be drawn if we broaden our analysis not only to the provision of investment services, but also to insurance, social security and credit services - services that most of the European 'universal' banks already provide. ${ }^{82}$

79 Consob (fn. 28), 18, reports that inconsistencies between self-assessed and actual knowledge range from $26 \%$ to $49 \%$, noting also that "the attitude to over-estimate one's own literacy" is "higher for advanced financial notions". On this issue, see also Gentile/Linciano/Soccorso (fn. 18), 28.

$80 \operatorname{ESMA}$ (fn. 20), 43. Extensively, see supra fn. 19.

81 ESMA (fn. 20), 43.

82 See supra fn. 31. As clearly pointed out in a survey conducted by the U.S. Investment Company Institute, most investors with an ongoing advisory relationships recur to advisers also because they want make sure "they are saving enough to meet their financial goals", properly assessing "their total financial picture" (Victoria Leonard-Chambers/ Michael Bogdan, "Why do Mutual Fund Investors Use Professional Advisers?", Investment Company Institute Fundamentals 2007, 5). More recently, Burke/Hung (fn. 1), 18 note that "there is evidence to suggest that individuals who receive advice tend to be more likely to have a plan for retirement, more likely to feel confident about their retirement preparations, and more likely to have retirement goals". For a similar conclusion, backed by empirical analysis, see also Michael S. Finke/Sandra J. Huston/William Waller, "Do Contracts Influence Comprehensive Financial Advice?”, Financial Services Review 2009, 177; Mitchell Marsden/Catbleen D. Zick/Robert N. Maye, "The Value of Seeking Financial Advice”, Journal of Family and Economic Issues 2011, 625; and Crystal R. Hudson/Lance Palmer, "Low-Income Employees: The Relationship Between Information from Formal Advisors and Financial Behaviors", Financial Services Review 2014, 25. 


\section{A New Role for Financial Advisors: The 'Simplified Advice'}

Having said that, it should be examined whether MiFID II allows for alternative solutions that can pave the way for a 'simplified advice', so to reduce the aforesaid advice gap. ${ }^{83}$ In particular, since the list of conditions laid down by art. 11, para. 2, let. $a$, of the Delegated Directive for the collection of inducements is "non-exhaustive" ${ }^{84}$ it should be investigated which features of the provision of investment advice: (i) while being 'compatible' with the business model of European distributors, (ii) could be deemed to enhance the quality of the service offered in a way that is compliant with the Delegated Directive, (iii) without enlarging the advice gap due to the excessive costs involved.

As already said, the Delegated Directive allows - under certain conditions - the collection of inducements even for merely executive investment services. ${ }^{85}$ With respect to these services, the only task performed by the financial intermediary is to reduce the transaction costs that may prevent investments from taking place (= finding a counterpart, drafting the contract, carrying out the operation); the distributor, instead, is not involved in the management of information asymmetries (not even in the weaker forms of spot advice) that usually characterizes every investment relationship. ${ }^{86}$

Because clients, in such circumstances, are not helped by the financial firm in the early selection of investments, the EU regulator tries to 'compensate' for the lack of advice by demanding that the distributor offers, at least, a wide range of third-party investment products. In this respect, the broader choice and the resulting possibility to better compare different financial instruments, coupled with the new product governance regime, are supposed to protect investors adequately. Therefore, it seems correct to conclude that both traditional 'spot advice' and the 'access to a wide range of investment products' represent - at the very end - two alternative (but equal) solutions to the same problem of the initial construction of the portfolio (using math, this concept can be summarized as follows: spot advice = merely executive investment service + access to a wide range of third-party investment products).

On the other hand, art. 11 of the Delegated Directive deems periodic advice 'comparable' to the provision of any other merely executive investment service which may also grant: (i) access to a wide range of third-party financial instru-

83 See Europe Economics (fn. 68), 62.

84 Recital 21 Delegated Directive and ESMA (fn. 40), para. 28 et seqq. Contra, Silverentand/Sprecher/Simons (fn. 1), p. 220.

85 Art. 11, para. 2, let. a, n. $\dddot{i i i}$, Delegated Directive; see supra sections 3 and 8.1.

86 See Andrea Perrone, Il diritto del mercato dei capitali, 2020, p. 203; Moloney (fn. 4), p. 805 . 
ments, relating to the initial choice of the investments, and (ii) "added-value tools" or other "periodic reports", for the on-going management of the portfolio. Obviously - since investors need to deal with both the construction of the portfolio and its management on their own - the decrease in benefits for the clients demands also (iii) a corresponding decrease in the overall amount of commissions and costs. Using math one again: periodic advice $=[$ (merely executive investment service + access to a wide range of third-party investment products $)^{87}+$ added value tools and other periodic reports $] *$ reduced commissions.

In this respect, it could also be asserted that the access to a wide range of investment products can be fairly substituted by the advice of the distributor on the initial construction of the portfolio (id est, by traditional spot advice, since the problem of the on-going management of the investments is still addressed by providing periodic reports). ${ }^{88}$

Hence, it may be correct to conclude that investment firms can lawfully collect inducements even if they provide traditional spot advice when, in addition: (i) they grant "added-value tools" or other "periodic reports" that can help clients "to take investment decisions" and "to monitor, model and adjust the range of financial instruments" in which they have invested; and (ii) the commissions paid by the client are proportional to the quality of the investment services offered. ${ }^{89}$ For descriptive purposes, we may call this investment service 'simplified advice'.

\section{Concluding Remarks}

As a generalized assessment of the conclusions reached in the previous section, this article identifies the apparent recurrence of two essential elements in every hypothesis laid down by art. 11 of the Delegated Directive for the licit collection of inducements. Indeed, such elements characterize MiFID II regulation and pave the way for the identification of new circumstances under which distributors can lawfully collect inducements, even outside the hypothesis explicitly listed.

In particular, these two fundamental elements are: (i) the provision of a 'wholecomprehensive' investment service, somehow capable of effectively encompassing every stage of the investment relationship, from the early assessment

87 Id est, 'spot advice': see the above paragraph.

88 See the first equation above, according to which: spot advice $=$ merely executive investment service + access to a wide range of third-party investment products.

89 As prescribed by art. 11, para. 2, let. a, n. iii, Delegated Directive. 
of clients' characteristics and objectives to the on-going management of the investments; and, above all, (ii) the introduction of a strict proportionality test between the overall amount of commissions paid by the investors and the effective quality of the investment service provided by the distributor. ${ }^{90}$

Such a proportionality test should play out within two different 'poles': on the lower end, FinTech services (especially robo-advisors), which can offer lowcost, high-tech, and standardized investment services based on the self-assessment of the investor; on the upper end, the provision of periodic advice, where clients are aided by the financial intermediary in every step of their investment.

Naturally, both sides of these 'poles' (more precisely, the overall amount of commissions and costs associated with each one) should be set only by market dynamics, so as to mitigate the risk that such a proportionality test may turn into a 'paternalistic price regulation'. Nevertheless, art. 11 of the Delegated Directive could still pose some enforcement challenges. Indeed, the aforesaid proportionality test entails wide discretion, as well as a judgement on the 'contents' and 'merits' of the investment service provided, ${ }^{91}$ thus making such scrutiny not fully compatible with a competitive market environment, nor with the powers that can be lawfully conferred to an independent authority.

From this perspective, shifting the basis for such a proportionality test from an external comparison between the common market price and the price actually offered by a specific investment firm, to an internal comparison between the prices offered for different services provided by the same distributor (or by a different firm belonging to the same financial conglomerate) could represent a well-balanced solution.

In particular, since inducements are paid by fund managers regardless of the investment service that clients have actually benefited from, distributors may be induced to 'spread' the costs for the provision of high-quality investment services among all their clients, even among those who benefit from different, lower-quality services. The distributors would be even more incentivized to do so because these latter investors are more frequently prone to cognitive biases

90 With regards to this latter, it may be also worth noting that such a 'proportionality principle' finally accomplishes the inducement regulation first introduced by MiFID I, where the strong opposition of market participants - fearing that such a test would have amounted to a kind of "price regulation" - suggested a milder approach. See Lannoo/ Casey (fn. 2), p. 118, noting that under MiFID I the proposal of a similar (even milder) regulation by CESR "elicited nothing less than a firestorm of protest from the industry".

91 Lannoo/Casey (fn. 2), p. 119. 
and cannot reliably and independently assess the real value of the advice actually provided, thus making transparency regulation less effective. ${ }^{92}$

On the contrary, under this new approach, if financial intermediaries decide to offer different 'kinds' of investment advice in order to meet the varying needs of their clients, then they must 'graduate' the costs and the commissions connected to the features of each specific investment service, thus preventing distributors from collecting the same amount of inducements for qualitatively different services (it has to be considered also that investment firms cannot lawfully provide periodic advice to smaller retail clients if the costs of such a service are no longer justified by tangible benefits for the relevant investor).

On the other hand, the implementation of such a proportionality test does not appear to entail excessive costs for the distributors. Indeed, as pointed out by art 12 of the Delegated Directive on independent advice and portfolio management, investment firms could put in place "mechanisms for transferring to the client" the amount of inducement received not corresponding to the service actually offered.

92 See supra fn. 46. 